\title{
Foreword to Empowerment and Innovation
}

This book aims to engage the interest of two constituencies. In career terms, the first operates at the sharp end of management and organization, in the practical world of affairs. This is an audience of prospective and practising managers, or, more specifically, people within this category who are favourably disposed towards employee empowerment, who articulate at least some commitment to the value of grassroots decision-taking, and who would do something positive to enact direct participation within their own situations. Although they represent the traditional target market for consultants and suppliers of prescriptive advice, these tend to be people who, through experience or involvement in management education, remain uneasy about the quality of the material that speaks directly to their concerns. Many of the readers in this category will, I'm sure, have encountered trite and unhelpful pronouncements and opportunistic interventions that draw a veil over the problems and issues that affect their practice. Some will have been disappointed or frustrated by 'how-to-do-it' techniques that are poorly grounded in the realities and dilemmas of organizational life. Collectively, this population is looking for more telling and potent management knowledge that can help them to make a difference in their working lives.

The people in our second constituency, namely critical social scientists and management commentators, provide the intellectual weight to support these everyday concerns, reinforcing the sense of inadequacy with prescriptive accounts of empowerment and participation. One of the most encouraging features of the past decade or so has been the dramatic expansion of work within the critical tradition of management studies that challenges the simplistic images and ideas traded in this area. As we shall see, social researchers are highly critical of a whole range of supposedly empowering initiatives, highlighting a contrast between rhetoric and substance, presenting rich empirical studies and offering a detailed analysis of contextualizing influences and constraints. The net result is a much stronger research base from which to explore the practical possibilities for empowerment. Yet this material is rarely 
absorbed into practitioner debates or followed through to agenda discussions that might assist front-line enthusiasts. Indeed, the findings of critical research regularly miss a practitioner audience, a situation that is largely attributable to the propensity of the research community to remain aloof.

Too many critical commentators unfortunately adopt an abstentionist position on practice, cutting their analyses short, stopping with the empirical results of their investigations, or demolishing guru prescriptions without considering the practical, organizational implications of their conclusions. Their work is loaded towards the early stages of what might usefully be called the full cycle of research. The major preoccupations, and indeed achievements, have been analytical and empirical, advancing our conceptual understanding of empowerment. Yet the momentum tends to stop at this point. The focus is almost exclusively on analysis and explanation, at the expense of following through to an explicit logic of practice. This dimension is conceded, by default, to consultants and prescriptive commentators who seem more interested or adept at engaging with practitioners, despite the negative reactions they often elicit. Even when attention is given to negative or unpalatable aspects of empowerment, the concern that critical writers demonstrate for staff on the receiving end is rarely matched by applied knowledge that can speak to those in the position, or with the inclination, to do something about it, to those who would become activists for change.

Some social scientists compound the access difficulty for managers by adopting a purist stance in their work, limiting their role to exploring ideas and articulating their sense of what ought to be in an ideal world, rather than addressing thorny issues of development. This is an understandable, if disappointing, position when so many research studies legitimately give rise to considerable pessimism about the obstacles to progress. For others, however, the flight from practical thinking is defensive and career-minded, rather than utopian.

Following the full research cycle from theoretical and investigative work to a consistent logic of practice is certainly fraught with difficulties. Generations of social scientists have issued warnings about the dangers of dual role compromises and the perils of dealing with practitioners. Eldridge (1981) provides a notable example with the call for researchers who would be relevant to beware. The gist of his argument is, quite rightly, that the challenge of being relevant often has strings attached. Recipients usually expect relevant research to be congenial rather than critical, useful on their own terms, otherwise it becomes unacceptable or threatening. This raises the spectre of conservatism that has long haunted the human relations tradition of management research, and which critical 
writers are determined to avoid. Hence, there are justifiable worries about 'managerialising the debate' (Thompson, 1986), or somehow encouraging the misappropriation of critical knowledge by enthusiasts for authoritarianism and tight labour control (Nord and Jermier, 1992).

Of course, the dangers of slippage from, or misappropriation of, progressive ideas are very real. However, it seems that there is also a thin line between caution and negativity. It can be easier and safer for critical commentators to rail against the prescriptive pronouncement of gurus and consultants, and to underscore the limited or tentative results of empowerment schemes, than extend their work to the challenge of managing and realizing change. Unhappily, social scientists can risk their research credentials in the realm of practice and open themselves to the charge of becoming ideologically unsound, possibilities that offer a powerful disincentive to applied work.

This is where we find the less excusable and debilitating side of critical management studies. Some contributions seem to equate the critical approach with an anti-management position, or at least their style can generate that perception among management readers. A deeply ingrained sense of 'them and us' feeds an oppositional stance in at least part of the critical literature, which aligns itself unambiguously with employee interests while presenting managers as the unquestioning and unitary agents of workplace misery. Mandel (1973) provides an obvious example, rejecting any link between contemporary management and progressive practice. His is not an abstentionist but a rejectionist position, saddling managers with an essential interest in labour control and dismissing empowerment as a means of concealing potential disagreements with staff.

Others produce negative assessments without such a rigidly servile image of managers. Hales (2000) provides a recent example, giving the impression, intentional or otherwise, that particular categories of middle and junior managers are against empowerment, or play calculating games with it to defend their own status and personal interests. This is theoretically positive insofar as it acknowledges the scope for managerial agency and choice, yet by reducing this to career politics and financial interests it reinforces the narrow, calculating and unhelpful image of management that survives within critical social research.

We are now at a point in history when people from a wide range of backgrounds, and with all sorts of personal values and beliefs, are employed under one management label or another. Some will have good reason to be worried about their jobs and to think defensively about their reactions to empowerment, especially where employers connect it with de-layering and downsizing policies. Yet management behaviour is not 
reducible to self-interest alone. For this category of humanity, as for any other, thoughts about personal advantage or disadvantage are cross cut by ethical considerations and various social values.

Contrary to the sentiments expressed by some critical writers, there are practising and aspiring managers who baulk at the traditions of tight labour control within modern organizations. There are managers who identify with critical writings and articulate a genuine concern for principles of fairness, justice and direct participation. Certainly, there are students in management education that would benefit from research that can lead to firmer views about how they can 'make a difference', how they can enact serious concerns and remain faithful to expressed values as they seek a living in management positions. More experienced hands can also be expected to benefit, empirical research indicating that personal concepts of self, integrity and morality continue to burn in managers throughout their careers, often adding a sense of struggle and dissatisfaction as they deal with everyday pressures and heartfelt contradictions (Watson, 1994).

Even if the suspicion remains that empowerment is somehow compromised or loaded towards employer interests, critical commentators could be more sensitive to the predicament of front-line managers who share a positive outlook. There could be more of an effort to acknowledge variability in the underlying values that move practitioners, and to relate this to a sense of management activism that might sustain progressive inclinations. This would enable the research community to reach beyond traditional debates and client groups, giving researchers the opportunity to apply their knowledge of organizational dilemmas and constraints, and to anticipate alternative possibilities, rather than occasionally wringing their hands about problems and poor experiences.

Initial pointers towards an applied research agenda have already been provided, albeit rather tentatively, by critical researchers who have taken employment in business school environments, and find that the issue has been forced for them as teachers of managers, especially on MBA and related programmes. Collins (2000) and Goulding and Currie (2000) provide examples of work that aims to package critical thinking and empirical research for a wider audience in management education, and to cultivate a more analytical and reflective practice. Using the phraseology adopted by Collins, this is 'critical-practical' in the sense of engaging with actors who may be committed to empowerment (Collins, 2000, p. 247) yet susceptible to technician thinking and the ill-conceived prescriptions of gurus and consultants.

As part of a broader attempt to inculcate the habits of critical scrutiny and promote active reflection, this line of development can be extremely 
useful, encouraging managers to 'stand back' from everyday pressures and question their attitudes, resources, activities and associations. However, it amounts to a partial and underdeveloped tendency, falling short of the effort needed to complete the full cycle of research.

In fact, some of the critical material that has emerged on reflective practice is disappointing, failing to match expressed aims with substantive content, and offering little more than a new spin on the old argument that 'there is nothing so practical as a good theory'. This is surely an accurate dictum when theoretical knowledge prompts an informed understanding of issues and an ability to interpret the problematics of empowerment, rendering practitioners less vulnerable to the toolkit views of consultants and the packaged accompaniments to passive management education. Yet the emphasis is still on a prior stage to action. What the researchers are aiming to provide is a sensitizing experience, equipping people with a greater ability to think and to play their own part in organizations as their awareness of conditions and constraints develops. The participants are then left to their own devices, to make their own sense of critical research and, more importantly, to find their own way of translating critical capabilities into a consistent practice. This is a truncated form of critical management studies.

Encouraging managers to reflect upon the principles and implications of their engagement with employees is only part of what is involved in pursuing the full cycle of critical research. Anticipating new possibilities and enlarging the collective stock of knowledge about alternative options is a neglected part of the agenda. Some of the most influential social scientists of the past half century, including Tom Burns (1967), C. Wright Mills (1973) and Richard Brown (1984), have argued along similar lines, that questioning, theorising and reflecting should be positively linked to the search for better ways of organizing and managing:

Thus it seems to me that an essential part of our task is to question and to investigate alternatives - activities which may often be combined ... few, if any, of us who try to find out and understand what work is like in our society will feel that there is no room for improvement; and exploring the conditions which make possible situations as they are is also, at least implicitly, to begin to establish how they might be different. (Brown, 1984, p. 317)

The purpose of sociology is to achieve an understanding of social behaviour and social institutions which is different from that current among the people through whose conduct institutions exist, an understanding which is not merely different but new and better. The practice of sociology is criticism ... It is the business of sociologists to conduct a critical debate with the public about its equipment of social institutions. (Burns, 1967, p. 366-7) 
For these figures, it is a matter of professional responsibility that critical commentators enact the full research cycle and 'follow through' on the practicalities of progressive management. This means ranging beyond theoretical conventions, the rules of evidence and sensitive reflection, in this case relating critical reviews of empowerment to envisaging and programme building activities that have practical merit.

This book makes a deliberate attempt to apply critical research to the problematic of enacting and sustaining direct participation, and to the challenge of addressing managers who would give practical meaning to the concept of employee empowerment. It is written polemically, as well as academically, to stimulate creative thinking about the everyday meaning of principled and reflective management, and the prospects for channelling research on the 'working out' of participation schemes into applied knowledge that can inform a progressive practice in the 'here and now'. This is an attempt to frame possibilities for innovative management without slipping to unrealistic or utopian assumptions.

There is a significant degree of correspondence between this approach and transformative projects in engineering and computing innovation, where critiques of orthodox prescriptions and standard ways of organizing and managing development work have paved the way to innovative possibilities and very practical alternatives. Theorist-practitioners such as Cooley (1980) and Rosenbrock (1990), and computing scientists in the participatory design community (Greenbaum and Kyng, 1991), have made a point of 'getting their hands dirty', of contemplating, devising, enacting, testing and evaluating new possibilities. Echoing the sentiments of Burns and Brown, they conceive of their role as not merely adding to the stock of available knowledge, but as challenging conventional ideas and finding ways to increase the congruence between empowering values and everyday job performance.

Drawing inspiration from this material, as well as telling episodes from empowerment initiatives in other contexts, critical research will be connected to three levels of practical engagement. The first concentrates on the linkage to scrutinizing, thinking and reflecting, building upon the emerging tendency to cultivate analytical and interpretive capabilities through critical management studies. However, it will add focus and specificity to established images of 'critical-practical' knowledge (Collins, 2000) by mapping essential characteristics and qualities that can enhance reflective thinking about empowerment. These will be summarized in the penultimate chapter, although from the earliest stages empirical research will be harnessed to flag some of the issues, difficulties and dilemmas bearing upon practical initiatives, so that enthusiasts 
are better equipped to apply judgemental and interpretive abilities in favour of empowerment in their own settings.

Shifting the emphasis from thinking to doing, the second level of practice considers engaging and enacting activities, recalling Pateman's (1970) attention to participatory competence and the learned capacity to overcome obstacles and inhibitions. Recognizing the managerial challenge of aligning principles and ambitions with situated learning and sustainable collaboration, down to earth guidance about what helps and hinders will be drawn from the case material assembled through the early chapters, and by introducing insights from research on community theatre. The latter is instructive because community theatre practitioners are also de facto managers. Their role is to help members of the public to engage in the creative process of producing involving drama or delivering theatre that connects with local issues and speaks to local concerns. This means co-ordinating and enabling participants from a wide range of situations and predicaments (including young offenders, retired people, disabled and handicapped groups and residents of housing estates, among many others) to reach their full potential and express their views in a telling and effective manner. The precariousness of empowerment can be very obvious in this context, hence practitioners tend to have a heightened sense of the intimacy between sensitive reflection and management activism. Their experience in moving between these dimensions, together with their accumulated knowledge of creative possibilities for engagement, have much wider applicability, bringing options for negotiating progress and sustaining empowerment more sharply into focus.

Finally, attention turns to public policy and questions about the regulatory framework within which voluntary commitments to empowerment are articulated. State and supra-state initiatives will be evaluated in terms of their enabling or constraining effects on local attempts to enact empowerment. The effectiveness of the relevant social provisions of the European Union will be a prominent consideration, though in pursuing the full cycle of research the analysis will extend into the developmental aspects of building and refining framework initiatives that are conducive to progressive management at the grassroots. 